\title{
Analysis on the Situation of Chinese Housing Bubble
}

\author{
Jingyu Yao \\ The Second High School Attath To Beijing Normal University, Beijing, China,100192 \\ *Corresponding author. Email: yao104728030@163.com
}

\begin{abstract}
Due to the continuously dramatic increase of the house prices in China, a question appears in front of the public asking if China has a housing bubble. This article first defines the term "housing bubble", giving a basic information about the main topic. And then it lists and explains several real life historical cases of the burst of the housing bubble both outside China and inside the mainland. By finally analyzing the research question deeply via two aspects, this article illustrates that China does not appear to have a nationwide housing bubble and it will not burst in the short term, but may generate such bubbles in the medium term or long term. Thus, the government and economists should still pay attention to China's real estate and think about the solution, preventing it from happening.
\end{abstract}

Keywords : Housing bubble, bubble economy, bubble burst, real estate, financial crisis, house price to income ratio, demand and supply

\section{INTRODUCTION}

Worldwide, there has been a rapid development of real estate which has led to the bubble economy. In China, an overheated real estate (the burst of the housing bubble) also happened in the 1990s, causing the economic and financial instability. It can be inferred that whether the real estate market has a healthy development or not has a profound impact on the steady development of the economy and the financing environment of enterprises. Therefore, the current situation of the real estate market in China is causing controversy among industries, academia and public: some people think that the real estate bubble has emerged so they should be vigilant and guard against, avoiding the burst of it; some people believe that there is no housing bubble at present, so it will not pose a threat to the country's economy; some people believe that although the real estate is not yet in a bubble state, they should still be guard on against the coming of it because of the boom of real estate economy. These arguments mainly stem from the rapid development of China's real estate market and the rising trend of house prices in recent years. So the article will mainly discuss whether a housing bubble appeared in China.

\section{THE DEFINITION OF HOUSING BUBBLE AND REAL ESTATE BUBBLE}

To analyze whether China has a housing bubble, first of all, the article would need to define the term "housing bubble" or "real estate bubble". [1] Charles $P$ -Kindleberger wrote the term "bubble" for "The New PalGrave A Dictionary Of Economics" saying that "bubbles can be defined as a sharp rise in the price of an asset or a series of assets in a continuous process. The initial price increases give rise to expectations that prices will go up further, thereby attracting new buyers--speculators who are generally buying and selling to make profits and are not interested in the use of assets and their profitability. As prices rise, there is often a reversal of expectations and a sharp fall in prices, which usually leads to financial crises. " Nevertheless, the sharp increase in prices is not a very well definition for bubble since sometimes price increases for good reason. For example, if a company developed an effective Covid-19 vaccine, its share price would probably increase sharply, which can be happened for good reasons. Therefore, this article would like to define bubble as the unrealistic high price of goods and assets (false prosperity) in the economic and financial fields. When asset prices rise to an unbearable level, they will inevitably plummet, as if the bubble burst, and the economy will begin to turn from prosperity to recession. The two characteristics of the bubble economy are that the supply and demand of the goods are seriously unbalanced -- the supply is far greater than the demand, and the atmosphere of speculative trading is very strong. The real estate bubble is a bubble economy based on real estate. It refers to the fact that the price of real estate 
is seriously deviated from the use value caused by real estate speculation.

\section{CASES IN OTHER COUNTRIES}

The two most famous cases of the real estate bubble burst in the world are Japan in the early 90s of last century and the US in 2008. The collapse of these two bubbles has had a profound impact on the country and even the whole world until now.

First of all, in the 1980s of last century, Japan experienced rapid development: the overall economy was becoming more and more, and a large amount of capital poured into real estate. After the "Plaza Accord" in 1985 , the Japanese yen rose sharply. The enthusiasm for domestic investment in Japan became increasingly fierce, and the land price had been unreasonably high. However, in March 1990, Japan issued the regulations on the total amount of land finance. This man-made policy led to the accelerated collapse of the bubble economy, which is already heading for a natural recession. The Bank of Japan also adopted a policy of financial contraction, which further led to the collapse of the bubble. House prices in Tokyo fell suddenly in a short time, and the bubble burst completely.

\section{Land prices in Japan}

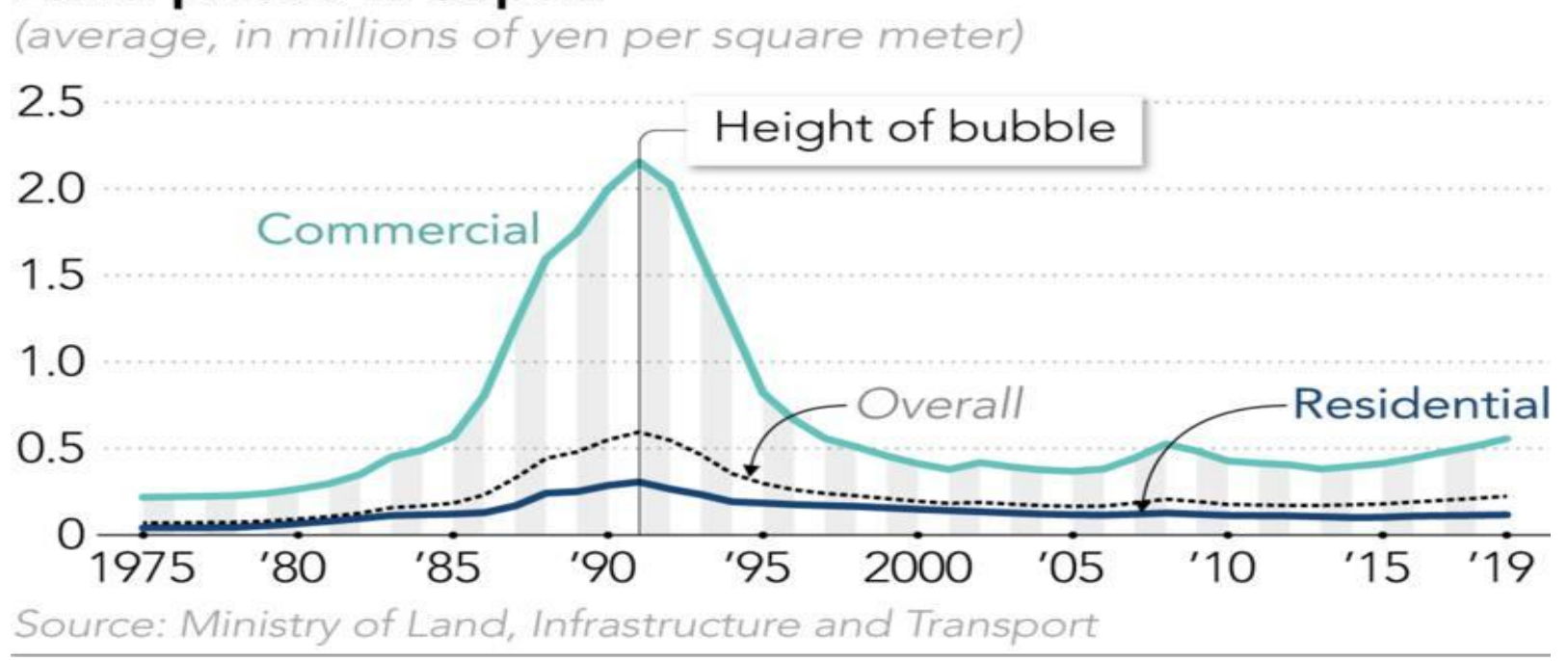

Figure 1. Land Prices in Japan. [2]

Secondly, during the global financial crisis, the Federal Reserve cut interest rates for the 13 time in a row, in order to offset the negative effects of the bubble bursting. There was no place for a large amount of money flowing into the market. It could only flow into real estate, which has risen the same as the increase of the past 30 years in only seven years. After the financial crisis, house prices in major cities in the United States fell more than $30 \%$ from their peak. 


\section{Residential and Commercial Property Price Indices 2000-2015}

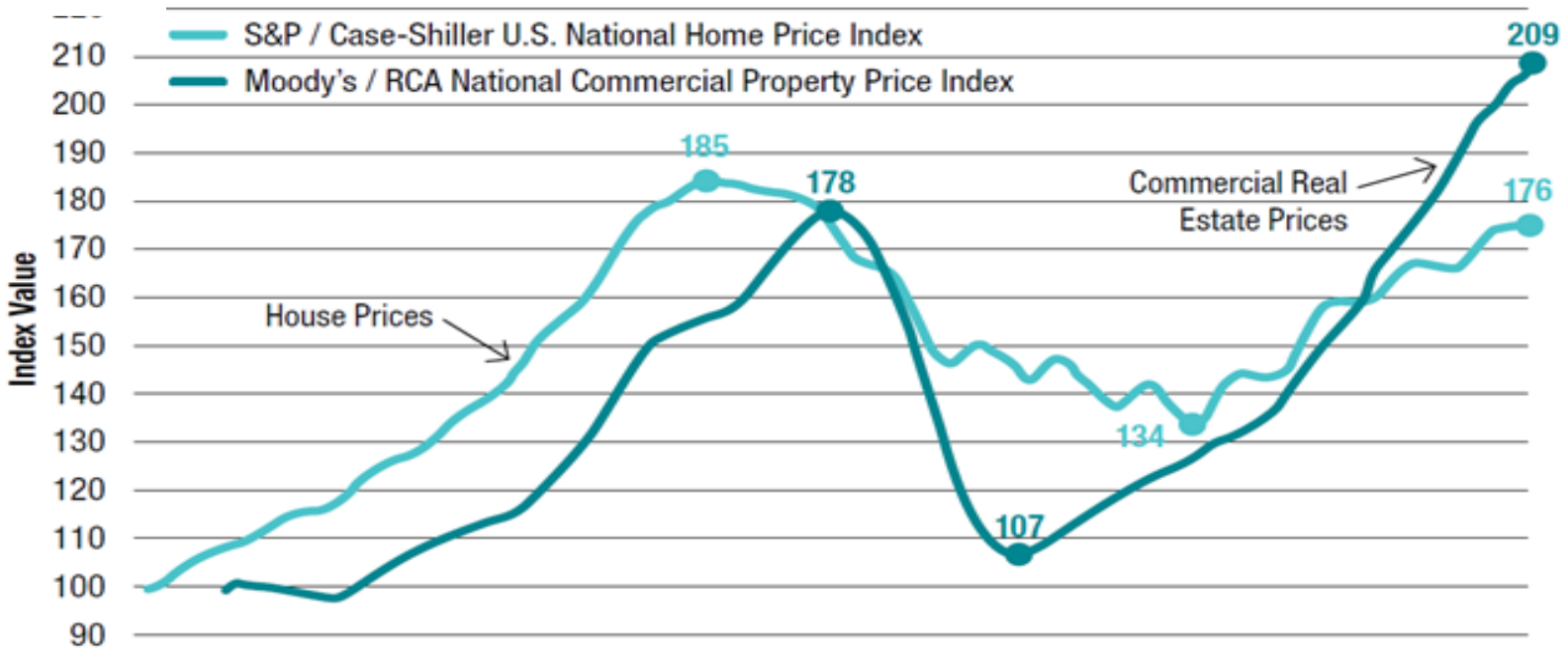

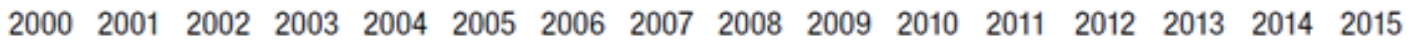

Figure 2. The Real Estate Double Bubble and Recovery. [3]

\section{CASES IN CHINA}

Tracing back to China, there are two places that are widely regarded as typical cases of the housing bubble burst. The first cause is in Hainan in the 1990s and the another case is in Hong Kong in 1997-2003, so the article will recall these two cases and analyze whether their economy collapsed for housing bubble or not.

Firstly, In 1988, Hainan province became the largest and only provincial-level Special Economic Zone in China. Investment from mainland provinces quickly poured into Hainan. Because of the weak industrial based in Hainan at that time, everyone turned their attention to real estate and spawned a huge real estate bubble. [4] In 1991, the average price of commercial housing in Hainan was 1400 yuan per square meter, and by 1993 , it had surged to 7500 yuan per square meter, and even the non-performing loan ratio of many banks was once as high as $60 \%$. However, prices would always fall back to the level of value. In June 1993, the Chinese government issued 16 articles to control credit, raise interest rates and strictly control real estate speculation. It burst the bubble instantly. In 1995, the real estate bubble burst in Hainan. Utill the second half of 2006, Hainan real estate, which suffered a lot of in the past years, began to show a slow recovery growth. However, the total turnover is still limited.

Secondly, since 1991, Hong Kong has implemented a "contractionary" land supply policy and stimulated it with low interest rates, which led to a sharp rise in house prices. In the past seven years, Hong Kong's house prices have increased fourfold. During the Asian financial crisis in 1997, Hong Kong kept the Hong Kong dollar and capital market with the help of the central government. However, the Asian financial crisis and afterwards the dotcom bubble bursting finally made the house prices in Hong Kong plummet tremendously in 1997, but eventually recovered and rose even higher. Thus, perhaps the declines in prices were just due to economic troubles or financial crisis in Asia rather than the bubble burst.

From here, Hong Kong case should not be a bubble and China should have a partial housing bubble due to its high housing prices. Nevertheless, it seems that it is difficult to find the third cases like them in China, so the article will discuss about the possibility it happens in the future.

\section{DISCUSSION}

Now, the worry about China's housing bubble is mainly due to the continuous rise in housing prices. After the housing reform in 1998, the housing market began to implement market-oriented trading. Since the beginning of the 21 st century, house prices began to rise rapidly. Although experiencing the global financial crisis, it continued to rise after 2010 , especially since 2015, house prices in major cities continued to rise, never falling.

Facing the rise of housing prices, whether China would have a bubble burst like Japan and the US, and whether prices would fall in the short term, or whether China have such bubble to burst are still questions raised here.

Firstly, the article would look at the rising trend of house prices in China. The figure 3 shows the fluctuation of China new house prices since 2006. It can be seen that from the national perspective, China's housing price shows obvious cyclical, sometimes high and sometimes low. Therefore, overall, China's housing prices are not rising all the way. Secondly, the article 


\section{China new house prices}

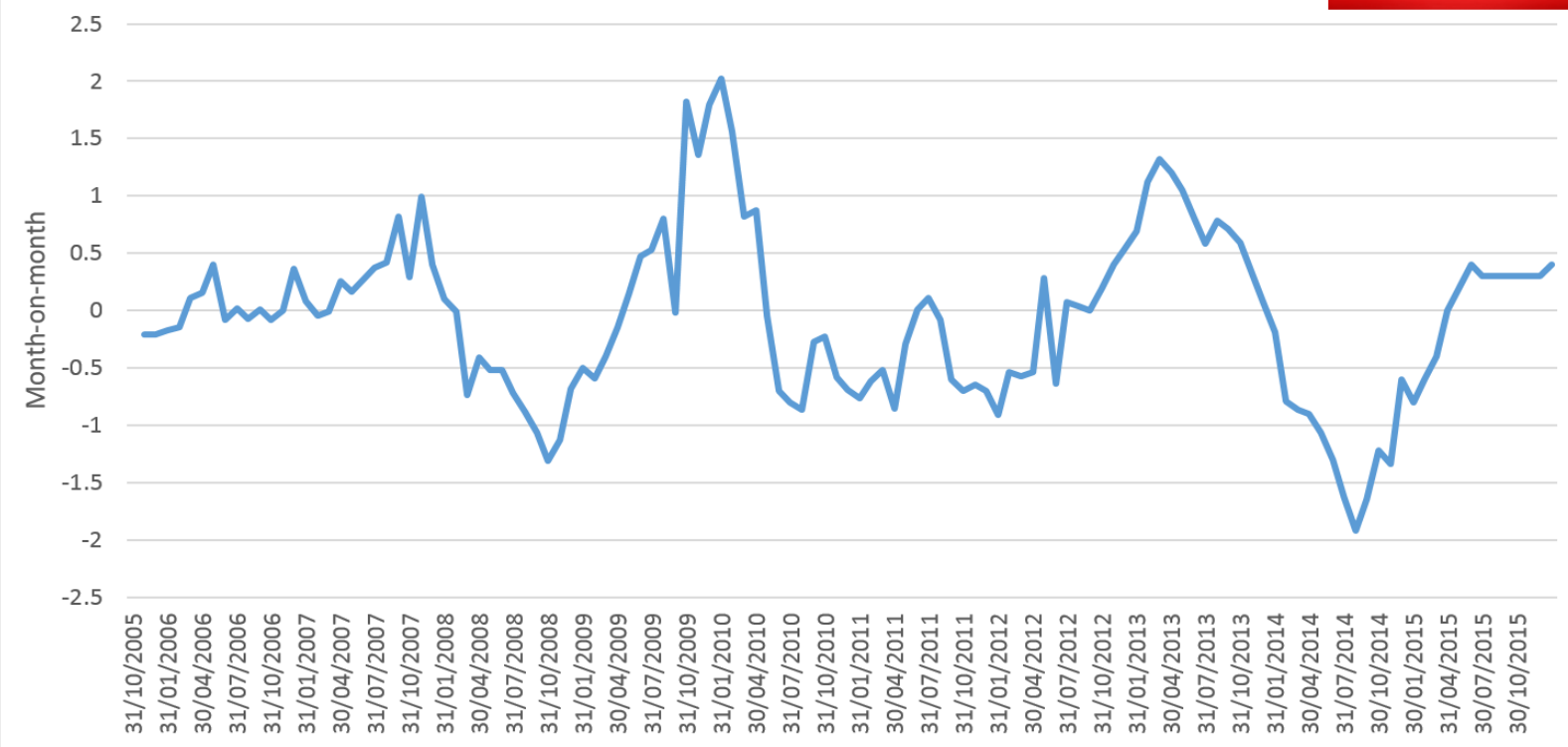

Figure 3. China New House Prices. [5]

\subsection{House Price to Income Ratio}

As the figure 4 shown, China has the highest ratio over other countries. However, an argument against the statement that price to income ratios is because of the housing bubble can still be provided. This ratio measures price to current income.

If incomes are expected rise quickly in the future, house price may increase since real estate developers think consumers will be more able to buy houses. Therefore, a high price to income ratio would happen. Generally, countries with rising incomes have high price to income ratios. By looking at the figure 5, we can see that the average expected wages in China is rising from 2010 to 2025. Consequently, the reason for high house price to income ratio in China may be something else other than housing bubble.

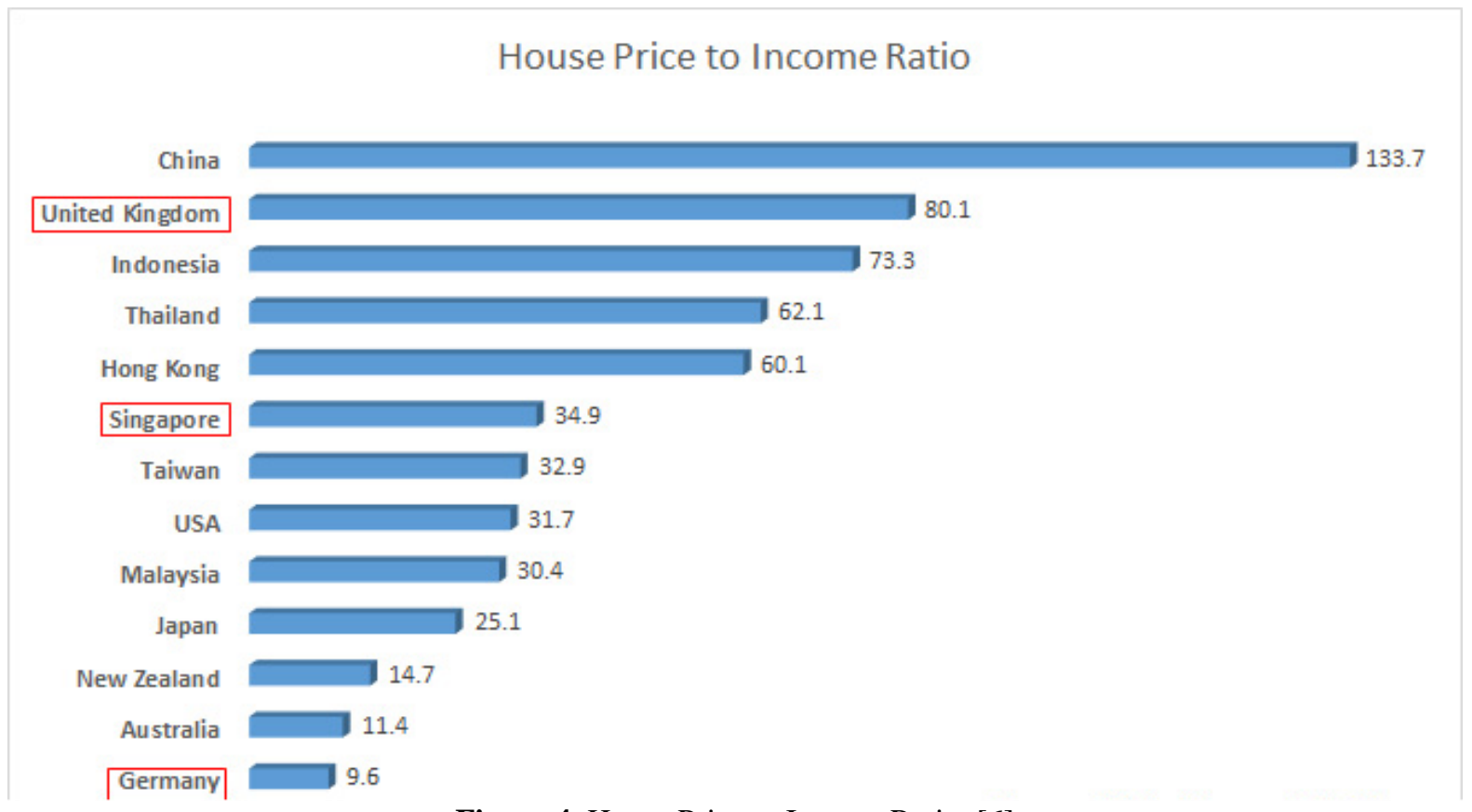

Figure 4. House Price to Income Ratio. [6] 


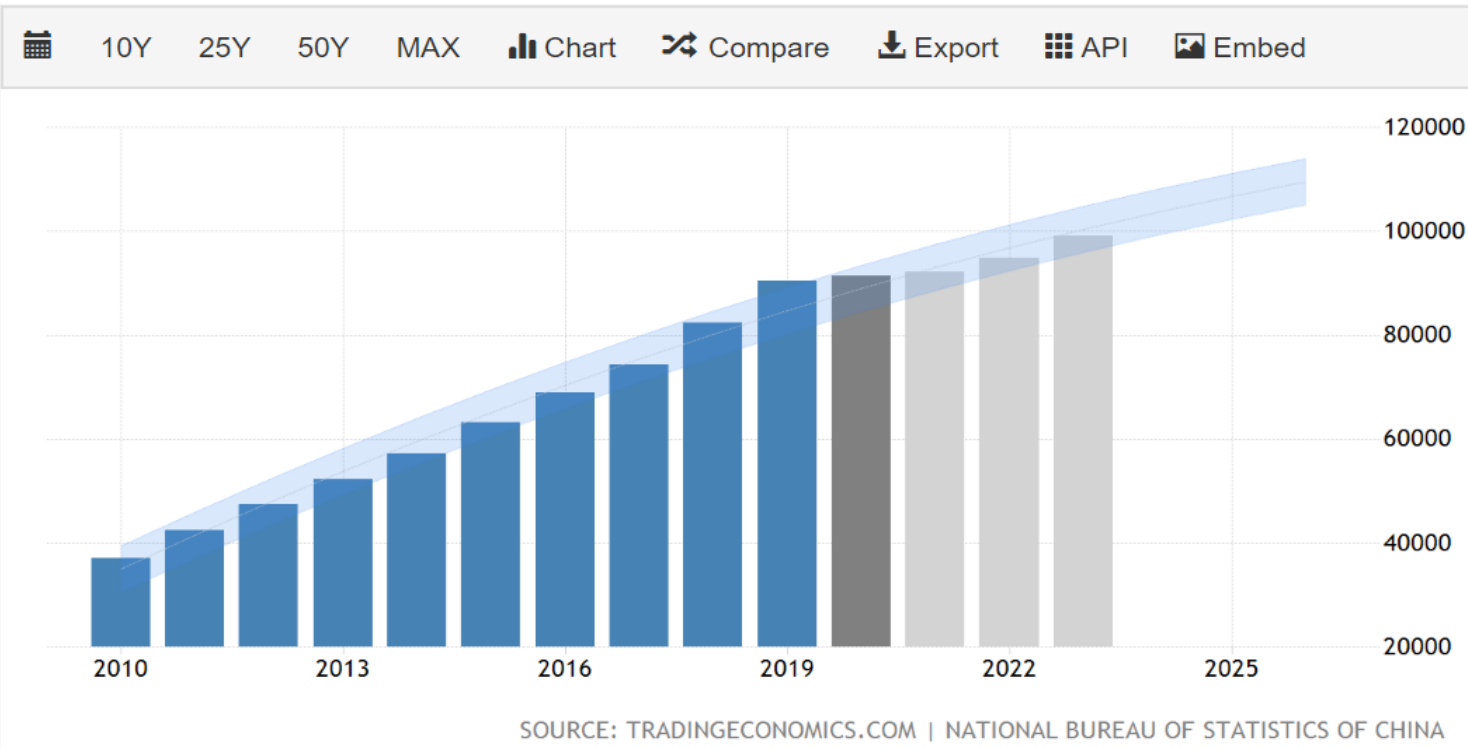

Figure 5. China Average Yearly Wage. [7]

\subsection{Supply and Demand of Houses in China}

Almost all asset price bubbles are caused by a large number of buying and selling demands, resulting in price rising. Supply is usually relatively stable in the short term. The same is true for real estate. Supply will not change dramatically in the short term.

However, in China, it is the housing supply factor that has caused the high housing prices in some cities. For a long time, the state of China's real estate market can be summed up in one sentence: where there is demand, there is no supply; where there is supply, there is no demand. Among them, "the place with demand" refers to the eastern region as the inflow area of population, and the "place without demand" refers to the central and western region as the outflow area of population. Supply refers to the land supply closely related to housing supply. If there is more land supply, more houses can be built and more houses will be provided.

Therefore, it can be concluded that the bubble factor is very little, because the real reason for high housing prices is the lack of housing supply.

\section{CONCLUSION}

To sum up the overall point of view, despite the fact that there are some early warning signs that housing prices is drastic increasing, and there may be some partial real estate bubbles in certain cities. As a whole, China does not appear to have a nationwide housing bubble. In fact, the high housing prices in big cities in eastern China can simply be explained by the law of supply and demand. In fact, academics have already had rigorous empirical research, which proves that the bubble factors of China's housing prices are relatively small. The reason behind the high housing prices is the so-called "balanced development" policy, causing the long-term mismatch of the supply and demand. In order to solve this problem, the government can promulgate policies to resolve this "crux" and truly realize the "balance between supply and demand" for the stable operation of housing prices.

In other words, in the short term, China will not have a larger nationwide real estate bubble. After all, it will still have room for the rise of prices, and the government is trying to control it well. However, it can not be ruled out that China's housing prices will not generate huge bubbles in the medium term or long term. Thus, the government and economists still need to really pay attention to China's real estate and think about the solution to avoid the irreversible losses led by the burst of housing bubbles.

\section{ACKNOWLEDGMENT}

Thanks professor Armstrong for informing the basic knowledge of housing bubble in developing the essay and Ms.Sun for helping revising the essay.

\section{REFERENCES}

[1] Chappelow, J. Housing Bubble Definition. Retrieved July 18, 2020.

https://www.investopedia.com/terms/h/housing_bu bble.asp

[2] Microsoft. Bing. 2020.3. https://cn.bing.com/images/search?view=detailV2 $\% 2$ Creal+estate+prices+in+japan+in+1978-200 
[3] Microsoft. Bing. 2020.3.

https://cn.bing.com/images/search?view=detailV2

$\% 2$ Creal+estate+prices+in+the+us+in+1978-2003

[4] The Event of The Housing Bubble in Hainan. Sanya Tourism Network. http://www.sycw.net/sanya/l.

[5] Microsoft.Bing. 2020.

https://cn.bing.com/images/search?view=detailV2 $\% 2$ CChina+new+house+price.

[6] Microsoft.Bing. 2020.

https://cn.bing.com/images/search?view=detailV2 $\% 2$ Chousing+prices+to+income+ratio+in+China.

[7] China Average Yearly Wages. Trading Economics. 2020. https://tradingeconomics.com/china/wages. 